\title{
Hematopoietic Stem Cell Transplantation for MDS
}

\author{
Matthias Bartenstein ${ }^{1}$ and $\mathbf{H}$. Joachim Deeg ${ }^{1,2}$ \\ ${ }^{1}$ Fred Hutchinson Cancer Research Center, Seattle, WA. \\ ${ }^{2}$ University of Washington School of Medicine, Seattle, WA.
}

\begin{abstract}
Hematopoietic stem cell transplantation (HSCT) offers potentially curative therapy for patients with myelodysplastic syndromes (MDS). However, as the majority of patients with MDS are in the $7^{\text {th }}$ or $8^{\text {th }}$ decade of life, conventional transplant regimens have been used only infrequently, and only with the development of reduced-intensity conditioning has transplantation been applied more broadly to older patients. Dependent upon disease status at the time of transplantation, 30-70\% of patients can be expected to be cured of their disease and survive long-term. However, post-transplant relapse and graft-versus-host disease (GVHD) remain problems and further instigations are needed.
\end{abstract}

\section{Keywords}

Transplantation for MDS; conditioning intensity; cytogenetics and relapse

\section{INTRODUCTION}

The myelodysplastic syndromes (MDS) comprise a heterogeneous group of clonal bone marrow diseases characterized by ineffective production of normal mature blood cells and peripheral blood cytopenias. ${ }^{1}$ Generally required for the diagnosis are dysplastic changes in blood and marrow cells. In approximately one-third of patients, MDS will eventually evolve to acute myeloid leukemia (AML).2 A detailed description of the disease characteristics, including the cellular and molecular biology of MDS, is provided elsewhere in this volume.

Infections due to neutropenia and neutrophil dysfunction represent the leading cause of death in MDS. ${ }^{1}$ Life-threatening bleeding due to thrombocytopenia is another complication directly attributable to marrow failure. ${ }^{1}$ The most frequent presentation, however, is anemia. ${ }^{3}$ Red blood cell transfusion dependence and the resulting iron overload may lead to additional organ complications, particularly in heart, liver and endocrine organs. ${ }^{4 ; 5}$

For most patients with MDS, chemotherapy alone is not a viable treatment option. Only about $40 \%$ of patients will achieve remissions, which are generally of short duration. ${ }^{6-8}$ For highrisk MDS patients, 3-year survival rates after chemotherapy are in the range of only $5 \% .{ }^{9}$

\footnotetext{
(C) 2009 Elsevier Inc. All rights reserved.

Corresponding Author: H. Joachim Deeg, M.D., Member, Fred Hutchinson Cancer Research Center, Professor, University of Washington School of Medicine, 1100 Fairview Avenue N, D1-100, Seattle, WA 98109-1024, jdeeg @ fhcrc.org.

Coauthor's Address: Matthias Bartenstein, MD, Fred Hutchinson Cancer Research Center, 1100 Fairview Avenue N, D1-100, Seatt, WA 98109-1024, m.bartenstein@gmail.com

Publisher's Disclaimer: This is a PDF file of an unedited manuscript that has been accepted for publication. As a service to our customers we are providing this early version of the manuscript. The manuscript will undergo copyediting, typesetting, and review of the resulting proof before it is published in its final citable form. Please note that during the production process errors may be discovered which could affect the content, and all legal disclaimers that apply to the journal pertain.
} 
Currently the only therapy with proven curative potential for MDS is hematopoietic stem cell transplantation (HSCT), $10^{-} 13$ with long-term survival rates between $25 \%$ and $70 \% .14^{-} 17$ However, HSCT carries a risk of toxicity and potentially fatal complications, particulary in older patients. Given the frequently slow progression in low-risk MDS, the risk of treatmentrelated mortality (TRM) must be carefully weighed against the potential benefits of transplantation. Patient characteristics, timing of transplantation, and choice of conditioning regimen have to be considered. Thus, the questions are: transplantation for whom, when, and how? Should induction chemotherapy be given before HSCT? What should be the source of stem cells? Should the graft be T-cell depleted? How can one optimize the rate of engraftment and the graft-versus-tumor effect (GvT) while minimizing the incidence of graft-versus-host disease (GvHD) and TRM? The present chapter will focus on these questions.

\section{GENERAL CONSIDERATIONS}

MDS originates in hematopoietic stem or precursor cells, and the goal of HSCT is to replace those cells and their progeny with cells from a healthy donor. Successful allogeneic HSCT requires that 1) healthy donor cells are able to establish themselves (engraft) in the patient, and 2) the abnormal (malignant) cells responsible for the patient's disease are eliminated or inactivated.

To allow donor cell engraftment it is generally necessary that the patient is "conditioned," i.e. the immunological barrier, which protects the body against intrusion by foreign organisms or cells, must be overcome. ${ }^{18} \mathrm{~T}$-cell mediated host-versus-graft reactions seem to be the main cause of rejection, in addition to natural killer (NK)-cell effects.

Conditioning can include various immunosuppressive drugs, chemotherapeutic agents or irradiation, and new regimens are continously being developed and tested. Regimens are often categorized as conventional/high-dose (myeloablative conditining [MAC]), reduced intensity (RIC), or low-dose/non-myeloablative conditioning (NMC). ${ }^{21}$ However, a review of the literature shows that there is a spectrum of regimens which basically form a continuum, 22 and any categorization must remain artificial. Nevertheless, it is clear that the extent of toxicity correlates with conditioning intensity, and in general the probability of relapse is higher the lower the regimen intensity.23 This is particularly true with transplantation for advanced disease. An important potential advantage of RIC is the ability of autologous marrow function to recover if the donor graft is rejected.

An undesired consequence of currently used conditioning regimens is that the defense against infectious organisms is also disrupted, and the fact that most conditioning regimens damage the anatomical tissue barriers (skin, mucosa) further enhances the risk of infections. This was one rationale for the development of RIC regimens, which cause less tissue toxicity than conventional high-dose regimens, which in turn translates into lower acute non-relapse mortality (NRM). The development of these RIC regimens has also allowed to offer HSCT to older individuals who, until recently, were not considered transplant candidates ${ }^{23 ;} 24$ and TRM in various HSCT regimens has steadily declined in recent years.25;26

A second purpose of the conditioning regimen is to ablate the abnormal cells responsible for the patient's disease. While the conditioning regimens are generally effective in killing a large proportion of tumor cells, we rely on the immuno-therapeutic effect of donor cells for complete disease eradication. The lower the conditioning intensity, the more the patient's cure will depend upon this GvT effect. ${ }^{22}$ In clinical studies, there is a strong correlation of GvT effect and GvHD, in particular chronic GvHD. ${ }^{18 ; 27}$ While recent research suggests that it may be possible to separate a GvT effect from the reactions that cause GvHD,28;29 clinically we have yet to show that such a separation is possible. Even if patients achieve remissions following HSCT, relapse remains a problem, especially in advanced MDS.30;31 The immunological 
effects of HSCT, and consequently the risk of relapse and GvHD, depend upon the conditioning regimen, the nature of the graft, i.e. degree of human leukocyte antigen (HLA)-match, stemcell source (bone marrow, peripheral blood or umbilical cord blood) and GvHD prophylaxis, among others.

Only about $25 \%$ of patients will have HLA identical sibling donors (or matched related donors other than a sibling). However, large volunteer "donor banks" have been set up, and currently, an HLA-matched unrelated donor can be identified for about 50-60\% of Caucasians; the proportion is lower for African Americans, and may be as low as 10\% in some ethnic minorities. 32;33 If a patient and sibling have inherited the same paternal and maternal chromosomes 6, they should be genotypically identical for HLA-A, -B, -C, -DR, and -DQ, i.e. show a "10 out of 10 " match. The only exception would be if a crossover has occurred. When we search for unrelated donors and typing by high resolution is available, we have the same objective of finding a "10 out of 10 match". Lesser degrees of matching may be acceptable for some indications. With increasing degrees of mismatching, there is a higher probability of nonengraftment (particularly with HLA-C disparities) and a higher probability of GVHD. For patients without an HLA-matched related or unrelated donor, cord blood cells or cells from a haploidentical related donor may offer alternatives.34-36 Cord blood has the advantage of "immaturity", allowing to transplant HLA-mismatched cells without a significant increase in GvHD incidence. A drawback is the limited number of cells available, often associated with a marked delay in engraftment.37 The use of two units of cord blood or in vitro "expansion" of the cord blood before infusion has partially overcome this limitation. $38^{-40}$

Initial results with haploidentical HSCT are encouraging. Graft failure presents only a minor problem, and GvHD rates have been surprisingly low, with relapse-free survival (RFS) and NRM comparing favourably with results from other HLA non-identical transplants. ${ }^{35}$ It is clear, of course, that in addition to HLA antigens, so-called "non-HLA" or "minor" antigens (which are presented by HLA antigens) are involved in allogeneic interactions and GVHD (otherwise, no GVHD should be observed in HLA-genotypically identical sibling transplants). It is currently not routine to type donor and patient for those minor antigens.

In addition, research in recent years has shown that antigens typically expressed on NK cells, in particular, KIR antigens are involved in donor/host interactions and may play an essential role in tumor cell elimination.

\section{RISK ASSESSMENT AND SCORING}

Several MDS scoring systems have been developed and are used to identify patients who are likely to benefit from HSCT.

\section{Multiparameter prognostic scoring systems}

The International Prognostic Scoring System (IPSS), ${ }^{2}$ used widely to assess patient prognosis, has also proven a reliable indicator of the probability of transplant success. The higher the IPSS score, the lower RFS.11;41 A major point of criticism is that the instrument's predictions are based on data from time of diagnosis, 42 although one recent study showed that if recalculated at the time of transplantation, the IPSS retained its predictive power. ${ }^{41}$ The more recently developed WHO Prognostic Scoring System (WPSS ${ }^{5}$ includes WHO classification, karyotype and transfusion dependence. In contrast to the IPSS it allows for real-time assessment of prognosis. A recent study validated its applicability to HSCT.43

Another recent addition is the Simplified MDS Risk Score 44 that includes poor performance status, older age, thrombocytopenia, anemia, increased marrow blasts, leukocytosis, chromosome 7 or complex $(\geq 3)$ abnormalities and earlier transfusions as adverse risk factors. 
It has been validated for secondary MDS and a cohort of de novo MDS patients. ${ }^{45}$ Whether this system is truly simpler than others remains to be seen, but its value might lie in the fact that it incorporates performance status, which in turn might reflect comorbidities. A possible relevance in the context of HSCT remains to be determined.

\section{Cytogenetics}

A patient's karyotype is the most powerful predictor of RFS after HSCT for MDS. ${ }^{2 ; 43 ; 46}$ This has led Armand et al. to re-examine the cytogenetic risk stratification of MDS in regards to the impact on transplant outcome. ${ }^{47}$ Their data, recently validated in a multi-center analysis, indicate that MDS patients can be separated into two groups, good/intermediate versus poorrisk cytogenetics, with significantly differing outcome post-HSCT. ${ }^{42 ; 48}$

\section{Flowcytometry}

Several studies have analyzed immunophenotypic aberrancies of MDS marrow cells and determined their prognostic relevance. ${ }^{49 ; 50}$ Wells et al. ${ }^{51}$ developed a flow scoring system and showed a correlation of the severity of flow-cytometric aberrancies and the probability of relapse after HSCT. Strikingly, this was true even for patients with less than 5\% marrow blasts at the time of HSCT. ${ }^{49}$ Presumably, differences in gene expression underly the observed immunophenotypic abnormalities, and gene expression profiling has been shown to predict the risk of progression of MDS to AML. ${ }^{52}$

\section{Transfusion dependence and iron overload}

Several recent studies $53^{-59}$ suggest that transfusion dependence (reflected in the WPSS) and iron overload have a negative impact on outcome after HSCT. The significance of elevated ferritin levels, however, is controversial, as ferritin may be elevated for various reasons, in particular inflammation. As such, a high ferritin level may reflect a different underlying disease process, rather than iron overload, although iron can contribute to inflammation. Liver iron content seems to be a more specific marker of iron overload, ${ }^{60 ; 61}$ with non-invasive assessment procedures being developed.56; 58 It has been postulated that treatment of iron overload may improve outcome following HSCT, ${ }^{55-58}$ although this is a matter of controversy.

Transfusion dependence is also linked to marrow fibrosis, the presence of which has long been recognized as being associated with accelerated disease progression in patients with MDS.

Recent studies ${ }^{58}$ confirm those findings, and one study at least has shown a negative impact of fibrosis on post-HSCT outcome, particularly in patients with more advanced MDS. ${ }^{62}$

\section{Age and comorbidity}

Until the mid 1990s few patients over 55 years were offered allogeneic HSCT63 due to higher NRM in older patients. As only about $25 \%$ of MDS patients are younger than 60 years, $2 ; 64$ efforts have focused on reducing the elevated risk of NRM associated with older age by modifying conditioning regimens (as discussed above), supportive care and complication management. ${ }^{63}$ Recent successfully transplanted cohorts included patients with median ages of 55-60 years, with some patients older than 70 years.63

Much of the negative impact of age on prognosis appears to be due to the frequency of comorbid conditions with older age. ${ }^{41}$ Sorror et al. developed a HCT-specific comorbidity index (HCT-CI)65 for risk assessment prior to transplantation, introducing objective laboratory and functional testing data, thereby modifying the Charlson Comorbidity Index.66 The instrument has been validated for lymphoma and myeloma patients, 67 and for a mixed patient sample. 68 A multivariate analysis showed that the HCT-CI had greater predictive power for toxicities, NRM and overall survival after RIC HSCT than the Karnofksy Performance Score (KPS), but 
these findings were not confirmed in a Canadian study. ${ }^{69}$ However, the instruments measure two distinct patients characteristics, as evidenced by their weak correlation with each other. A combination of comorbidity and performance status assessment allows a more refined riskstratification for HSCT.65

\section{TIMING OF TRANSPLANTATION}

Determining the optimal timing of HSCT for MDS has proven difficult since it involves weighing the benefit of early transplantation (reduced risk of disease progression and relapse) with high TRM (in some studies as high as 20-25\%), especially in patients in whom disease progression (even without HSCT) may be slow. ${ }^{2 ;} 11$

Generally, shorter disease duration before HSCT is linked to improved overall survival, decreased TRM and increased RFS. Lower blast count (based on FAB classification) and younger age are also linked to more favorable outcome. ${ }^{70}$ Cutler et al. used a Markov model, involving a nontranplantation cohort and two patient cohorts receiving HLA-identical sibling transplants after high-dose conditioning, to determine the optimal timing of HSCT for MDS. They showed that patients with high or intermediate- 2 risk by IPSS did benefit from early transplantation, while transplantation should be delayed for low-risk patients until evidence of disease progression. Intermediate-1 patients should probabaly be evaluated on a case by case basis.71 While this analysis was restricted to patients transplanted from HLA-identical siblings, most transplant centers apply this approach also to patients transplanted from unrelated donors. 72

Al-Ali et al. found that outcome after allogeneic (and autologous) HSCT was best if transplantation was performed between 6-12 months after diagnosis, with higher overall survival and lower TRM than observed in patients transplanted later. They attributed the negative effect of later transplantation to frequent blood transfusion, longer duration of pancytopenias, and increased risk of progression during the waiting period for HSCT. ${ }^{73}$

If transplantation has to be delayed, for example because of a lengthy search for an unrelated donor (median time 2-3 months;74 median time from diagnosis to HSCT 12.9 months in the US;75 median search duration 22 days for 549 patients in Germany76), 'bridging' treatment with hypo-methylating agents may delay progression to AML before HSCT.72 Such a strategy is especially relevant for MDS patients with IPSS intermediate-2 or high-risk disease, where the average time to AML progression may be short. $^{2}$

\section{PRETRANSPLANT INDUCTION CHEMOTHERAPY AND THE USE OF HYPOMETHYLATING DRUGS}

Studies linking elevated pre-transplant blast counts to increased risk of relapse ${ }^{17}$ have led to investigations into the benefit of pre-transplant induction chemotherapy ${ }^{30 ; 77}$ for RFS after HSCT. Induction chemotherapy plays an important role in autologous HSCT, since this transplant modality requires that the patient be in remission; ${ }^{46}$ for allogeneic HSCT, the indication is less clear. Several retrospective studies suggest that patients who achieve remission after induction chemotherapy have a lower risk of relapse after HSCT than patients who do not respond to induction chemotherapy. ${ }^{72 ; 78 ; 79}$ It is still controversial whether this approach affects RFS. ${ }^{78 ; 80 ; 81}$

It is conceivable that the effect of pre-transplant chemotherapy consists in selecting treatmentsensitive patients. ${ }^{43}$ To address these questions, the European Bone Marrow Transplant (EBMT) group is currently conducting a prospective randomized phase III trial investigating 
the impact of pre-HSCT induction therapy on relapse rates after HSCT (EBMT Study code: Allo-MDS2×2).

Hypomethylating agents are emerging as an alternative to classic induction chemotherapy.72 In a recent retrospective study of therapy before allogeneic HSCT, overall survival, RFS, and cumulative incidence of relapse after 1 year were $47 \%, 41 \%$, and $20 \%$, respectively, for patients with MDS (and CML) receiving 5-azacytidine, compared to 60\%, 51\%, and 32\% for non-5azacytidine treated patients. Pre-transplant administration of 5-azacytidine resulted in a trend to reduced risk of relapse.82 In 17 patients with MDS, the hypomethylating drug 2-deoxy-5azacytidine (decitabine) did not negatively affect toxicity after HSCT, and disease downstaging may improve HSCT outcome.83 However, responses to both, 5-azacytidine and decitabine are often delayed; in cases requiring urgent action (e.g. due to high risk of progression), induction chemotherapy may be preferable. 30

\section{CONDITIONING REGIMENS}

Intensive research in recent years has been geared toward minimizing the toxicity while optimizing the efficacy of conditioning regimens. However, there is no one-size-fits-all conditioning regimen. ${ }^{46}$ Instead, conditioning should be tailored to diagnosis, disease stage, patient age, prior therapy, comorbidities and the other components of HSCT, such as donor and stem cell source. ${ }^{11 ; 31}$

While conventional conditioning is associated with a lower risk of relapse, ${ }^{30}$ its toxicity makes it unsuitable for many patients with comorbidities, and it is generally only offered to patients under 65 or 60 years of age with suitable related or unrelated donors, respectively. ${ }^{11}$ For MDS patients over 60 years, ${ }^{64}$ and those with comorbidities, RIC is a viable alternative. While it is associated with a higher risk of relapse, this is possibly offset by lower TRM, ${ }^{84 ; 85}$ thereby offering equivalent overall survival and RFS, ${ }^{30 ; 46 ; 84-86}$ although no prospective randomized study of comparable patients has been conducted so far. Even patients over 70 years have been transplanted successfully using RIC. ${ }^{87 ; 88}$ These results from retrospective studies should be interpreted with caution, because of likely bias in patient selection. ${ }^{85 ; 89 ; 90}$ Only prospective studies will allow a definite comparison.

\section{DONOR SELECTION}

The policy at most centers currently is to search for HLA-identical siblings. If no sibling is available, then an attempt is made to identify HLA-matched unrelated donors. Cord blood is being used as a third option. However, various centers have focused their research on the use of cord blood and might use this source of stem cells even instead of searching for a living unrelated donor. Further, efforts are underway to utilize haploidentical transplants more frequently since preliminary observations suggest a low rejection frequency and a surprisingly low incidence of GVHD. However, this approach must be considered investigational, and further data are required before firm recommendations can be made.

\section{STEM CELL SOURCE AND MANIPULATION}

Stem cells obtained by bone marrow (BM) aspiration, umbilical cord blood cells (UCB) and granulocyte colony stimulating factor (G-CSF) mobilized peripheral blood progenitor cells (PBPC) lead to different outcomes, due to different GvHD and GvT effects, the number and nature of cells transplanted, and the relative maturity or activation of cells. ${ }^{18}$

A retrospective EMBT study, 91 in agreement with data from FHCRC12 showed that the use of G-CSF mobilized PBPC for HSCT from related donors in patients with MDS was associated with lower treatment failure rates (relapse and refractory disease) than the use of marrow in 
all MDS subgroups except refractory anemia.. Data from a recent Markov decision model of choice between BM and PBPC grafts in HLA-matched related donor HSCT92 involving 1111 adult patients conditioned with high-dose regimens and given unmanipulated grafts, showed significantly higher survival and better quality of life with PBPC, mainly due to lower risk of relapse, despite a higher incidence of GvHD. How PBSC compares to BM in unrelated HSCT is controversial,93;94 but a randomized prospective study in unrelated transplant recipients was just recently completed, and results are pending (Blood and Marrow Transplant Clinical Trials Network protocol 0201).

A third option is, as discussed, the use of UCB transplantation $34 ; 37 ; 39 ; 95 ; 96$ The introduction of two-unit transplants 39 has helped to overcome restrictions associated with the low cell dose of UCB units, 95 and in vitro expansion of UCB is emerging as a further option (reviewed in38). Few studies are available on the use of UCB in MDS (reviewed in97).

\section{WHAT CAN PATIENTS WITH MDS EXPECT FROM TRANSPLANTATION?}

As discussed, many factors influence the outcome of HSCT. Two recent reviews offer a comprehensive compilation of current results. Kindwall-Keller and Isola ${ }^{97}$ reviewed results of 24 studies that used high-dose conventional transplant conditioning and 30 studies that used RIC between 2000 and 2008. Oliansky et al. ${ }^{46}$ attempted an "evidence based review" which included articles published between 1990 and 2008. Following below is a discussion of selected reports.

Warlick et al. studied 84 patients transplanted with marrow from related or unrelated donors or cord blood, following conditioning with conventional or RIC regimens. ${ }^{30}$ At 1 year, overall survival was $48 \%$, cumulative relapse incidence $23 \%$, and RFS $38 \%$. The corresponding figures at 5 years were $31 \%, 25 \%$ and $29 \%$, respectively. TRM at one year was $39 \%$, and the incidence of acute GvHD was $43 \%$ for grades II-IV. The incidence of chronic GvHD at 1 year was $15 \%$. RFS did not differ significantly by graft source or conditioning regimen. The probability of relapse was $18 \%$ for patients with $\leq 5 \%$ myeloblasts at HSCT and $35 \%$ for patients with $\geq 5 \%$ blasts. In patients with less than $5 \%$ blasts, conventional conditioning was associated with a lower risk of relapse compared to RIC (9\% vs 31\%), but the difference was non-significant in patients with more than $5 \%$ blasts. Conditioning intensity did not affect overall survival or RFS.

A study by de Witte et al. included an EBMT registry cohort of 374 patients with refractory anaemia (RA) or RA with ringed sideroblasts (RARS) receiving HLA-matched grafts after various conditioning regimems. ${ }^{25}$ At 4 years, overall survival was $52 \%$, RFS $48 \%$, relapse $15 \%$, and NRM $37 \%$. After adjusting for confounding factors, multivariate analysis showed increased risk of relapse after RIC compared to conventional conditioning, with a hazard ratio (HR) of 2.8. However, overall survival and RFS did not differ, due to lower NRM after RIC, with a HR of 0.8. HSCT from unrelated donors was associated with a lower relapse risk (HR 0.6), but higher NRM (HR 1.4) and overall survival did not differ significantly from that with related donors. Outcome did not differ between BM and PBSC grafts, while T-cell depletion was associated with higher NRM. Older age and transplantation more than 12 months after diagnosis adversely affected outcome.

An FHCRC study 98 analyzed outcomes in 257 patients with secondary MDS, including 103 whose disease had progressed to AML. Grades II-IV acute GvHD occurred in $67 \%$ of patients, and $57 \%$ developed chronic GvHD. The 5-year incidence of relapse was 33\% for tAML, 36\% for RAEB and $12 \%$ for RA/RARS. The 5-year RFS was $29 \%$ overall, $19 \%$ for tAML, $25 \%$ for RAEB, and $41 \%$ for RA/RARS. Outcomes were compared with results in 339 patients transplanted for de novo MDS/t-AML. Multivariate analysis failed to show significant differences between the two cohorts after adjusting for cytogenetic risk. Relapse probability 
and RFS significantly correlated with disease stage ( $\mathrm{p}<.001)$ and karyotype $(\mathrm{p}<.001)$. Patients receiving unrelated donor transplants $(\mathrm{n}=122)$ had a lower risk of relapse $(\mathrm{p}=.003)$ and higher RFS ( $\mathrm{p}=.02)$ compared to those receiving grafts from related donors. Conditioning with $(\mathrm{t})$ BUCY ( $\mathrm{n}=93)$ was associated with the highest RFS (43\%) and lowest NRM (28\%).

In a retrospective multicenter study, Martino et al. ${ }^{85}$ analyzed HSCT outcomes in 836 patients with MDS transplanted from HLA-identical sibling donors after RIC $(\mathrm{n}=215)$ or conventional conditioning $(\mathrm{n}=621)$. For the conventional and RIC cohorts, 3 -year NRM was $32 \%$ vs. $22 \%$, overall survival $45 \%$ vs. $41 \%$, and RFS $41 \%$ vs. $33 \%$. The cumulative incidence of acute GvHD was $58 \%$ vs. $43 \%$ at 100 days post-transplantation. Within 1 year, chronic GvHD developed in $52 \%$ vs. $45 \%$ of patients. Lack of complete remission before HSCT ( $\mathrm{p}=.001)$, poor-risk karyotype ( $\mathrm{p}=.03)$, diagnosis of tAML $(\mathrm{p}=.03)$, and age older than 50 years $(\mathrm{p}=.05)$ negatively affected RFS.

Lim et al. ${ }^{99}$ prospectively evaluated the outcomes of 75 patients undergoing alemtuzumabbased RIC followed by unrelated donor HSCT. Actuarial 3-year TRM, RFS and overall survival, respectively, were $24 \%, 55 \%$ and $59 \%$ for patients with RCMD (n=28) and 44\%, $18 \%$ and $18 \%$, respectively, for patients with RAEB 1 and $2(\mathrm{n}=15)$. In multivariate analysis, HLA-mismatch adversely affected TRM, RFS and overall survival. Disease status at transplantation and comorbidity significantly influenced overall survival.

\section{MANAGING RELAPSE AFTER HSCT}

While TRM after HSCT has progressively declined over the past decade, due to intesive efforts aimed at optimizing conditioning regimens, relapse has remained a major problem in all reports, but more so with RIC. Whether post-HSCT monitoring for disease progression or recurrence will be useful in instituting therapy for minimal residual disease (MRD), found helpful in other diseases, remains to be shown. BM cyto- and histomorphology, cytogenetic monitoring, PCR-assessment of molecular markers, assessment of donor-host chimerism and immunophenotyping ${ }^{100}$ have all been applied.

In a recent study, MRD was found to significantly influence outcome after HSCT. ${ }^{101}$ MRD was assessed by counting cells with a "leukemia associated phenotype" as determined by flowcytometry 100 days after transplant. Not surprisingly, patients with low MRD $\left(<10^{-3}\right)$ had better overall survival (73\% vs. $25 \%$ ) and RFS (74\% vs. $17 \%$ ) compared to those with high MRD $\left(\geq 10^{-3}\right)$. Patients with low tumor burden and GvHD might benefit from intensified immunosuppression, reaping the benefit of reduced GvHD while running only a small risk of relapse due to reduced GvL effects. ${ }^{101}$

Various teams have administered pre-emptive donor lymphocyte infusions (DLI) in patients with relapse. ${ }^{102-} 108$ It is not clear, however, how effective such a strategy will be eventually. Chemotherapy has generally been disappointing, and second HSCT in adults have been associated with a low success rate. 109

\section{AUTOLOGOUS HSCT}

If no suitable matched donor is available, autologous transplantation of stem cells harvested during remission may be an option. Autologous HSCT has the advantage of transplantation without the risk of GvHD. Unfortunately, this also means the absence of a GvT effect, and consequently, increased risk of relapse. ${ }^{73 ; 110 ; 111}$ With the development of UCB transplants and the use of haploidentical donors autologous transplants are being used rather infrequently in patients with MDS. 


\section{SUMMARY AND CONCLUSIONS}

Hematopoietic stem cell transplantation is currently the only treatment modality with proven curative potential. With the development of reduced-intensity conditioning regimens, it has been possible to offer HSCT to patients in the 7th and even 8th decade of life, an important consideration in view of age distribution of MDS. Further, the development of large unrelated donor registries, the availability of cord blood as a source of stem cells, and, most recently, the renewed interest in using haploidentical donors for transplantation allows to offer HSCT to a growing number of patients. While $20-25 \%$ of patients may suffer from chronic medical problems after HSCT, more than 70\% report their quality of life as being "good to excellent" 1-2 years after transplantation. ${ }^{92}$ It is clear, however, that despite all progress that has been made, with some patients now followed for more than 25 years after successful transplantation, disease recurrence and GVHD remain major hurdles. Great hopes are placed on immunotherapy after transplantation, but progress has been slow. With the availability of approved drugs for the treatment of MDS, ongoing studies are exploring the incorporation of those agents into the overall transplant approach. It will be of interest to follow both the impact of pre-transplant therapy and post-transplant adjuvant treatment with hypomethylating agents or lenalidomide on long-term success.

\section{Acknowledgments}

This work was supported in part by NIH grant HL036444, Bethesda, MD.

\section{REFERENCES}

1. Steensma DP, Bennett JM. The myelodysplastic syndromes: diagnosis and treatment (Review). Mayo Clin.Proc 2006;81:104-130. [PubMed: 16438486]

2. Greenberg P, Cox C, LeBeau MM, et al. International scoring system for evaluating prognosis in myelodysplastic syndromes (erratum appears in Blood 1998 Feb 1;91(3):1100). Blood 1997;89:2079_ 2088. [PubMed: 9058730]

3. Greenberg PL, Baer MR, Bennett JM, et al. Myelodysplastic syndromes: clinical practice guidelines in oncology [erratum appears in J Natl Compr Canc Netw. 2006 Mar;4(3):table of contents Note: dosage error in text]. Journal of the National Comprehensive Cancer Network 2006;4:58-77. [PubMed: 16403405]

4. Gattermann N. The treatment of secondary hemochromatosis. Deutsches Arzteblatt International 2009;106:499-504. [PubMed: 19727383]

5. Malcovati L, Germing U, Kuendgen A, et al. Time-dependent prognostic scoring system for predicting survival and leukemic evolution in myelodysplastic syndromes. J.Clin.Oncol 2007;25:3503-3510. [PubMed: 17687155]

6. de Witte T, Suciu S, Peetermans M, et al. Intensive chemotherapy for poor prognosis myelodysplasia (MDS) and secondary acute myeloid leukemia (sAML) following MDS of more than 6 months duration. A pilot study by the Leukemia Cooperative Group of the European Organisation for Research and Treatment in Cancer (EORTC-LCG). Leukemia 1995;9:1805-1811. [PubMed: 7475266]

7. Estey E, Thall P, Beran M, Kantarjian H, Pierce S, Keating M. Effect of diagnosis (refractory anemia with excess blasts, refractory anemia with excess blasts in transformation, or acute myeloid leukemia [AML]) on outcome of AML-type chemotherapy. Blood 1997;90:2969-2977. [PubMed: 9376577]

8. Ruutu T, Hanninen A, Jarventie G, et al. Intensive chemotherapy of poor prognosis myelodysplastic syndromes (MDS) and acute myeloid leukemia following MDS with idarubicin and cytarabine. Leuk.Res 1997;21:133-138. [PubMed: 9112430]

9. Beran M. Intensive chemotherapy for patients with high-risk myelodysplastic syndrome (Review). Int.J.Hematol 2000;72:139-150. [PubMed: 11039661]

10. Nachtkamp K, Kundgen A, Strupp C, et al. Impact on survival of different treatments for myelodysplastic syndromes (MDS). Leuk.Res 2009;33:1024-1028. [PubMed: 19185917] 
11. Scott B, Deeg HJ. Hemopoietic cell transplantation as curative therapy of myelodysplastic syndromes and myeloproliferative disorders. Best Practice \& Research Clinical Haematology 2006;19:519-522. [PubMed: 16781487]

12. Deeg HJ, Storer B, Slattery JT, et al. Conditioning with targeted busulfan and cyclophosphamide for hemopoietic stem cell transplantation from related and unrelated donors in patients with myelodysplastic syndrome. Blood 2002;100:1201-1207. [PubMed: 12149198]

13. de Lima M, Anagnostopoulos A, Munsell M, et al. Nonablative versus reduced-intensity conditioning regimens in the treatment of acute myeloid leukemia and high-risk myelodysplastic syndrome: dose is relevant for long-term disease control after allogeneic hematopoietic stem cell transplantation. Blood 2004;104:865-872. [PubMed: 15090449]

14. Deeg, HJ. Hematopoietic cell transplantation for myelodysplastic syndrome and myeloproliferative disorders. In: Appelbaum, FR.; Forman, SJ.; Negrin, RS.; Blume, KG., editors. Thomas' Hematopoietic Cell Transplantation. Oxford, UK: Wiley-Blackwell; 2009. p. 827-844.

15. de Lima M, Giralt S. Allogeneic transplantation for the elderly patient with acute myelogenous leukemia or myelodysplastic syndrome (Review). Semin.Hematol 2006;43:107-111. [PubMed: 16616044]

16. de Witte T, Hermans J, Vossen J, et al. Haematopoietic stem cell transplantation for patients with myelo-dysplastic syndromes and secondary acute myeloid leukaemias: a report on behalf of the Chronic Leukaemia Working Party of the European Group for Blood and Marrow Transplantation (EBMT). Br.J.Haematol 2000;110:620-630. [PubMed: 10997974]

17. Sierra J, Pérez WS, Rozman C, et al. Bone marrow transplantation from HLA-identical siblings as treatment for myelodysplasia. Blood 2002;100:1997-2004. [PubMed: 12200358]

18. Welniak LA, Blazar BR, Murphy WJ. Immunobiology of allogeneic hematopoietic stem cell transplantation (Review). Annu.Rev.Immunol 2007;25:139-170. [PubMed: 17129175]

19. Yu J, Venstrom JM, Liu XR, et al. Breaking tolerance to self, circulating natural killer cells expressing inhibitory KIR for non-self HLA exhibit effector function after T cell-depleted allogeneic hematopoietic cell transplantation. Blood 2009;113:3875-3884. [PubMed: 19179302]

20. Ruggeri L, Capanni M, Urbani E, et al. Effectiveness of donor natural killer cell alloreactivity in mismatched hematopoietic transplants. Science 2002;295:2097-2100. [PubMed: 11896281]

21. Bacigalupo A, Ballen K, Rizzo D, et al. Defining the intensity of conditioning regimens: working definitions. Biol Blood Marrow Transplant 2009;15:1628-1633. [PubMed: 19896087]

22. Deeg HJ, Maris MB, Scott BL, Warren EH. Optimization of allogeneic transplant conditioning: not the time for dogma. Leukemia 2006;20:1701-1705. [PubMed: 16888618]

23. Baron F, Sandmaier BM. Current status of hematopoietic stem cell transplantation after nonmyeloablative conditioning. Curr.Opin.Hematol 2005;12:435-443. [PubMed: 16217159]

24. Valcarcel D, Martino R. Reduced intensity conditioning for allogeneic hematopoietic stem cell transplantation in myelodysplastic syndromes and acute myelogenous leukemia (Review). Curr.Opin.Oncol 2007;19:660-666. [PubMed: 17906468]

25. de Witte T, Brand R, van Biezen A, et al. Allogeneic stem cell transplantation for patients with refractory anaemia with matched related and unrelated donors: delay of the transplant is associated with inferior survival. Br.J.Haematol 2009;146:627-636. [PubMed: 19604243]

26. Castro-Malaspina H, Harris RE, Gajewski J, et al. Unrelated donor marrow transplantation for myelodysplastic syndromes: outcome analysis in 510 transplants facilitated by the National Marrow Donor Program. Blood 2002;99:1943-1951. [PubMed: 11877264]

27. Laport GG, Sandmaier BM, Storer BE, et al. Reduced-intensity conditioning followed by allogeneic hematopoietic cell transplantation for adult patients with myelodysplastic syndrome and myeloproliferative disorders. Biol Blood Marrow Transplant 2008;14:246-255. [PubMed: 18215785]

28. Kawase T, Matsuo K, Kashiwase K, et al. HLA mismatch combinations associated with decreased risk of relapse: implications for the molecular mechanism. Blood 2009;113:2851-2858. [PubMed: 18997170]

29. Michalek J, Collins RH, Durrani HP, et al. Definitive separation of graft-versus-leukemia-and graftversus-host-specific CD4+ T cells by virtue of their receptor beta loci sequences. PNAS 2003;100:1180-1184. [PubMed: 12531922] 
30. Warlick ED, Cioc A, DeFor T, Dolan M, Weisdorf D. Allogeneic stem cell transplantation for adults with myelodysplastic syndromes: importance of pretransplant disease burden. Biol Blood Marrow Transplant 2009;15:30-38. [PubMed: 19135940]

31. Ramakrishnan, A.; Deeg, HJ. Allogeneic hematopoietic cell transplantation for patients with myelodysplastic syndrome and myeloproliferative disorders. In: Soiffer, RJ., editor. Hematopoietic Stem Cell Transplantation. Totowa, NJ: Humana Press; 2008. p. 167-182.

32. Rocha V, Locatelli F. Searching for alternative hematopoietic stem cell donors for pediatric patients (Review). Bone Marrow Transplant 2008;41:207-214. [PubMed: 18084331]

33. Petersdorf, EW. Hematopoietic cell transplantation from unrelated donors. In: Appelbaum, FR.; Forman, SJ.; Negrin, RS.; Blume, KG., editors. Thomas' Hematopoietic Cell Transplantation. Oxford, UK: Wiley-Blackwell; 2009. p. 675-691.

34. Brunstein CG, Weisdorf DJ. Future of cord blodd for oncology uses. Bone Marrow Transplant. 2009 October 5; prepublished online doi:10.1038/bmt.2009.286.

35. Aversa F. Haploidentical haematopoietic stem cell transplantation for acute leukaemia in adults: experience in Europe and the United States (Review). Bone Marrow Transplant 2008;41:473-481. [PubMed: 18176612]

36. Luznik L, O'Donnell PV, Symons HJ, et al. HLA-haploidentical bone marrow transplantation for hematologic malignancies using nonmyeloablative conditioning and high-dose, post-transplantation cyclophosphamide. Biol Blood Marrow Transplant 2008;14:641-650. [PubMed: 18489989]

37. Koh LP, Chao NJ. Umbilical cord blood transplantation in adults using myeloablative and nonmyeloablative preparative regimens (Review). Biol Blood Marrow Transplant 2004;10:1-22. [PubMed: 14752775]

38. Kelly SS, Sola CBS, de Lima M, Shpall E. Ex vivo expansion of cord blood. Bone Marrow Transplant. 2009 October 5; 9999; prepublished online doi:10.1038/bmt.2009.284.

39. Barker JN, Weisdorf DJ, Defor TE, et al. Transplantation of 2 partially HLA-matched umbilical cord blood units to enhance engraftment in adults with hematologic malignancy. Blood 2005;105:13431347. [PubMed: 15466923]

40. Delaney C, Gutman JA, Appelbaum FR. Cord blood transplantation for haematological malignancies: conditioning regimens, double cord transplant and infectious complications (Review). Br.J.Haematol 2009;147:207-216. [PubMed: 19796270]

41. Lee J-H, Lee J-H, Lim S-N, et al. Allogeneic hematopoietic cell transplantion for myelodysplastic syndrome: prognostic significance of pre-transplant IPSS score and comorbidity. Bone Marrow Transplant. 2009 August 10; 9999;prepublished online doi:10.1038/bmt.2009.190.

42. Armand P, Kim HT, Cutler CS, et al. A prognostic score for patients with acute leukemia or myelodysplastic syndromes undergoing allogeneic stem cell transplantation. Biol Blood Marrow Transplant 2008;14:28-35. [PubMed: 18158958]

43. Alessandrino EP, Della Porta MG, Bacigalupo A, et al. WHO classification and WPSS predict posttransplantation outcome in patients with myelodysplastic syndrome: a study from the Gruppo Italiano Trapianto di Midollo Osseo (GITMO). Blood 2008;112:895-902. [PubMed: 18497321]

44. Kantarjian H, O'Brien S, Ravandi F, et al. Proposal for a new risk model in myelodysplastic syndrome that accounts for events not considered in the original International Prognostic Scoring System. Cancer 2008;113:1351-1361. [PubMed: 18618511]

45. Breccia M, Cannella L, Stefanizzi C, et al. WPSS versus simplified myelodysplastic syndrome risk score: Which is the best tool for prediction of survival in myelodysplastic patients? Leuk.Res 2009;33:e93-e94. [PubMed: 19070364]

46. Oliansky DM, Antin JH, Bennett JM, et al. The role of cytotoxic therapy with hematopoietic stem cell transplantation in the therapy of myelodysplastic syndromes: an evidence-based review. Biol Blood Marrow Transplant 2009;15:137-172. [PubMed: 19167676]

47. Armand P, Kim HT, DeAngelo DJ, et al. Impact of cytogenetics on outcome of de novo and therapyrelated AML and MDS after allogeneic transplantation. Biol Blood Marrow Transplant 2007;13:655664. [PubMed: 17531775]

48. Armand P, Deeg HJ, Kim HT, et al. Multicenter validation study of a transplantation-specific cytogenetics grouping scheme for patients with myelodysplastic syndromes. Bone Marrow Transplant. 2009 September 28; prepublished online doi:10.1038/bmt.2009.253. 
49. Scott BL, Wells DA, Loken MR, Myerson D, Leisenring WM, Deeg HJ. Validation of a flow cytometric scoring system as a prognostic indicator for posttransplantation outcome in patients with myelodysplastic syndrome. Blood 2008;112:2681-2686. [PubMed: 18606877]

50. Stetler-Stevenson M, Arthur DC, Jabbour N, et al. Diagnostic utility of flow cytometric immunophenotyping in myelodysplastic syndrome. Blood 2001;98:979-987. [PubMed: 11493442]

51. Wells DA, Benesch M, Loken MR, et al. Myeloid and monocytic dyspoiesis as determined by flow cytometric scoring in myelodysplastic syndrome correlates with the IPSS and with outcome after hemopoietic stem cell transplantation. Blood 2003;102:394-403. [PubMed: 12649150]

52. Mills KI, Kohlmann A, Williams PM, et al. Microarray-based classifiers and prognosis models identify subgroups with distinct clinical outcomes and high risk of AML transformation of myelodysplastic syndrome. Blood 2009;114:1063-1072. [PubMed: 19443663]

53. Kataoka K, Nannya Y, Hangaishi A, et al. Influence of pretransplantation serum ferritin on nonrelapse mortality after myeloablative and nonmyeloablative allogeneic hematopoietic stem cell transplantation. Biol Blood Marrow Transplant 2009;15:195-204. [PubMed: 19167679]

54. Maradei SC, Maiolino A, de Azevedo AM, Colares M, Bouzas LF, Nucci M. Serum ferritin as risk factor for sinusoidal obstruction syndrome of the liver in patients undergoing hematopoietic stem cell transplantation. Blood 2009;114:1270-1275. [PubMed: 19401560]

55. Lee JW, Kang HJ, Kim EK, Kim H, Shin HY, Ahn HS. Effect of iron overload and iron-chelating therapy on allogeneic hematopoietic SCT in children. Bone Marrow Transplant. 2009 April 27; prepublished online doi:10.1038/bmt.2009.88.

56. Busca A, Falda M, Manzini P, et al. Iron overload in patients receiving allogeneic hematopoietic stem cell transplantation: quantification of iron burden by superconducting quantum interference device (SQUID) and therapeutic effectiveness of phlebotomies. Biol Blood Marrow Transplant. 2009 September 18; prepublished online doi:10.1016/j.bbmt.2009.09.011.

57. Mahindra A, Bolwell B, Sobecks R, et al. Elevated pretransplant ferritin is associated with a lower incidence of chronic graft-versus-host disease and inferior survival after myeloablative allogeneic haematopoietic stem cell transplantation. Br.J.Haematol 2009;146:310-316. [PubMed: 19508292]

58. Cazzola M, Della Porta MG, Malcovati L. Clinical relevance of anemia and transfusion iron overload in myelodysplastic syndromes (Review). Hematology 2008:166-175. [PubMed: 19074076]

59. Armand P, Kim HT, Cutler CS, et al. Prognostic impact of elevated pretransplantation serum ferritin in patients undergoing myeloablative stem cell transplantation. Blood 2007;109:4586-4588. [PubMed: 17234738]

60. Sucak GT, Yegin ZA, Ozkurt ZN, Aki SZ, Karakan T, Akyol G. The role of liver biopsy in the workup of liver dysfunction late after SCT: is the role of iron overload underestimated? Bone Marrow Transplant 2008;42:461-467. [PubMed: 18604240]

61. Strasser SI, Kowdley KV, Sale GE, McDonald GB. Iron overload in bone marrow transplant recipients. Bone Marrow Transplant 1998;22:167-173. [PubMed: 9707025]

62. Scott BL, Storer BE, Greene JE, Hackman RC, Appelbaum FR, Deeg HJ. Marrow fibrosis as a risk factor for post-transplant outcome in patients with advanced MDS or AML with multilineage dysplasia. Biol Blood Marrow Transplant 2007;13:345-354. [PubMed: 17317588]

63. Marcondes M, Deeg HJ. Hematopoietic cell transplantation for patients with myelodysplastic syndromes (MDS): when, how and for whom? Best Practice \& Research Clinical Haematology 2008;21:67-77. [PubMed: 18342814]

64. Ma X, Does M, Raza A, Mayne ST. Myelodysplastic syndromes: incidence and survival in the United States. Cancer 2007;109:1538-1542.

65. Sorror M, Storer B, Sandmaier BM, et al. Hematopoietic cell transplantation-comorbidity index and Karnofsky performance status are independent predictors of morbidity and mortality after allogeneic nonmyeloablative hematopoietic cell transplantation. Cancer 2008;112:1992-2001. [PubMed: 18311781]

66. Charlson ME, Pompei P, Ales KL, MacKenzie CR. A new method of classifying prognostic comorbidity in longitudinal studies: development and validation. J.Chronic Dis 1987;40:373-383. [PubMed: 3558716]

67. Farina L, Bruno B, Patriarca F, et al. The hematopoietic cell transplantation comorbidity index (HCTCI) predicts clinical outcomes in lymphoma and myeloma patients after reduced-intensity or non- 
myeloablative allogeneic stem cell transplantation. Leukemia 2009;23:1131-1138. [PubMed: 19194465]

68. Kataoka K, Nannya Y, Ueda K, Kumano K, Takahashi T, Kurokawa M. Differential prognostic impact of pretransplant comorbidity on transplant outcomes by disease status and time from transplant: a single Japanese transplant centre study. Bone Marrow Transplant. 2009 August 17; prepublished online doi:10.1038/bmt.2009.194.

69. Guilfoyle R, Demers A, Bredeson C, et al. Performance status, but not the hematopoietic cell transplantation comorbidity index (HCT-CI), predicts mortality at a Canadian transplant center. Bone Marrow Transplant 2009;43:133-139. [PubMed: 18762762]

70. Runde V, de Witte T, Arnold R, et al. Bone marrow transplantation from HLA-identical siblings as first-line treatment in patients with myelodysplastic syndromes: early transplantation is associated with improved outcome. Chronic Leukemia Working Party of the European Group for Blood and Marrow Transplantation. Bone Marrow Transplant 1998;21:255-261. [PubMed: 9489648]

71. Cutler CS, Lee SJ, Greenberg P, et al. A decision analysis of allogeneic bone marrow transplantation for the myelodysplastic syndromes: delayed transplantation for low-risk myelodysplasia is associated with improved outcome. Blood 2004;104:579-585. [PubMed: 15039286]

72. Kindwall-Keller T, Isola LM. The evolution of hematopoietic SCT in myelodysplastic syndrome (Review). Bone Marrow Transplant 2009;43:597-609. [PubMed: 19252532]

73. Al Ali HK, Brand R, van Biezen A, et al. A retrospective comparison of autologous and unrelated donor hematopoietic cell transplantation in myelodysplastic syndrome and secondary acute myeloid leukemia: a report on behalf of the Chronic Leukemia Working Party of the European Group for Blood and Marrow Transplantation (EBMT). Leukemia 2007;21:1945-1951. [PubMed: 17611571]

74. Howe, CWS.; Radde-Stepaniak, T. Hematopoietic cell donor registries. In: Thomas, ED.; Blume, KG.; Forman, SJ., editors. Hematopoietic Cell Transplantation. Boston, MA: Blackwell Science; 1999. p. 503-512.

75. Karanes C, Nelson GO, Chitphakdithai P, et al. Twenty years of unrelated donor hematopoietic cell transplantation for adult recipients facilitated by the National Marrow Donor Program (Review). Biol Blood Marrow Transplant 2008;14:8-15. [PubMed: 18721775]

76. Hirv K, Bloch K, Fischer M, Einsiedler B, Schrezenmeier H, Mytilineos J. Prediction of duration and success rate of unrelated hematopoietic stem cell donor searches based on the patient's HLA-DRB1 allele and DRB1-DQB1 haplotype frequencies. Bone Marrow Transplant 2009;44:433-440. [PubMed: 19290000]

77. Maris MB, Sandmaier BM, Storer BE, et al. Allogeneic hematopoietic cell transplantation after fludarabine and $2 \mathrm{~Gy}$ total body irradiation for relapsed and refractory mantle cell lymphoma. Blood 2004;104:3535-3542. [PubMed: 15304387]

78. Scott BL, Storer B, Loken M, Storb R, Appelbaum FR, Deeg HJ. Pretransplantation induction chemotherapy and posttransplantation relapse in patients with advanced myelodysplastic syndrome. Biol Blood Marrow Transplant 2005;11:65-73. [PubMed: 15625546]

79. Yakoub-Agha I, de La Salmonière P, Ribaud P, et al. Allogeneic bone marrow transplantation for therapy-related myelodsyplastic syndrome and acute myeloid leukemia: a long-term study of 70 patients-report of the French Society of bone marrow transplantation. J.Clin.Oncol 2000;18:963971. [PubMed: 10694545]

80. Nakai K, Kanda Y, Fukuhara S, et al. Value of chemotherapy before allogeneic hematopoietic stem cell transplantation from an HLA-identical sibling donor for myelodysplastic syndrome. Leukemia 2005;19:396-401. [PubMed: 15674354]

81. de Lima M, Couriel D, Thall PF, et al. Once-daily intravenous buslfan and fludarabine: clinical and pharmacokinetic results of a myeloabltive, reduced-toxicity conditioning regimen for allogeneic stem cell transplantation in AML and MDS. Blood 2004;104:857-864. [PubMed: 15073038]

82. Pidala J, Kim J, Field T, et al. Infliximab for managing steroid-refractory acute graft-versus-host disease. Biol Blood Marrow Transplant 2009;15:1116-1121. [PubMed: 19660725]

83. De Padua SL, de Lima M, Kantarjian H, et al. Feasibility of allo-SCT after hypomethylating therapy with decitabine for myelodysplastic syndrome. Bone Marrow Transplant 2009;43:839-843.

[PubMed: 19151791] 
84. Alyea EP, Kim HT, Ho V, et al. Impact of conditioning regimen intensity on outcome of allogeneic hematopoietic cell transplantation for advanced acute myelogenous leukemia and myelodysplastic syndrome. Biol Blood Marrow Transplant 2006;12:1047-1055. [PubMed: 17067911]

85. Martino R, Iacobelli S, Brand R, et al. Retrospective comparison of reduced-intensity conditioning and conventional high-dose conditioning for allogeneic hematopoietic stem cell transplantation using HLA-identical sibling donors in myelodysplastic syndromes. Blood 2006;108:836-846. [PubMed: 16597592]

86. Scott BL, Sandmaier BM, Storer B, et al. Myeloablative vs nonmyeloablative allogeneic transplantation for patients with myelodysplastic syndrome or acute myelogenous leukemia with multilineage dysplasia: a retrospective analysis. Leukemia 2006;20:128-135. [PubMed: 16270037]

87. Maris M, Storb R. The transplantation of hematopoietic stem cells after nonmyeloablative conditioning: A cellular therapeutic approach to hematologic and genetic diseases. Immunol Res 2003;28:13-24. [PubMed: 12947221]

88. Platzbecker U, Ehninger G, Schmitz N, Bornhäuser M. Reduced-intensity conditioning followed by allogeneic hematopoietic cell transplantation in myeloid diseases (Review). Ann.Hematol 2003;82:463-468. [PubMed: 12910373]

89. Sorror ML, Maris MB, Storb R, et al. Hematopoietic cell transplantation (HCT)-specific comorbidity index: a new tool for risk assessment before allogeneic HCT. Blood 2005;106:2912-2919. [PubMed: 15994282]

90. Sorror M, Maris M, Baron F. A modified hematopoietic cell transplantation (HCT)-specific comorbidity index. Blood 2004;104(Part 1):324a-325a. \#1146.(Abstract).

91. Guardiola P, Runde V, Bacigalupo A, et al. Retrospective comparison of bone marrow and granulocyte colony-stimulating factor-mobilized peripheral blood progenitor cells for allogeneic stem cell transplantation using HLA identical sibling donors in myelodysplastic syndromes. Blood 2002;99:4370-4378. [PubMed: 12036864]

92. Pidala J, Anasetti C, Kharfan-Dabaja MA, Cutler C, Sheldon A, Djulbegovic B. Decision analysis of peripheral blood versus bone marrow hematopoietic stem cells for allogeneic hematopoietic cell transplantation. Biol Blood Marrow Transplant 2009;15:1415-1421. [PubMed: 19822301]

93. Pulsipher MA, Chitphakdithai P, Miller JP, et al. Adverse events among 2408 unrelated donors of peripheral blood stem cells: results of a prospective trial from the National Marrow Donor Program. Blood 2009;113:3604-3611. [PubMed: 19190248]

94. Eapen M, Logan BR, Confer DL, et al. Peripheral blood grafts from unrelated donors are associated with increased acute and chronic graft-versus-host disease without improved survival. Biol Blood Marrow Transplant 2007;13:1461-1468. [PubMed: 18022576]

95. Rocha V, Gluckman E. Improving outcomes of cord blood transplantation: HLA matching, cell dose and other graft- and transplantation-related factors. Br.J.Haematol 2009;147:262-274. [PubMed: 19796275]

96. Ooi J. The efficacy of unrelated cord blood transplantation for adult myelodysplastic syndrome. Leuk.Lymphoma 2006;47:599-602. [PubMed: 16690517]

97. Harrison SJ, Cook G, Nibbs RJ, Prince HM. Immunotherapy of multiple myeloma: the start of a long and tortuous journey (Review). Expert Review of Anticancer Therapy 2006;6:1769-1785. [PubMed: 17181491]

98. Chang CK, Storer BE, Scott BL, et al. Hematopoietic cell transplantation in patients with myelodysplastic syndrome or acute myeloid leukemia arising from myelodysplastic syndrome: similar outcomes in patients with de novo disease and disease following prior therapy or antecedent hematologic disorders. Blood 2007;110:1379-1387. [PubMed: 17488876]

99. Lim ZY, Ho AY, Ingram W, et al. Outcomes of alemtuzumab-based reduced intensity conditioning stem cell transplantation using unrelated donors for myelodysplastic syndromes. Br.J.Haematol 2006;135:201-209. [PubMed: 16939494]

100. Bacher U, Zander AR, Haferlach T, Schnittger S, Fehse B, Kroger N. Minimal residual disease diagnostics in myeloid malignancies in the post transplant period (Review). Bone Marrow Transplant 2008;42:145-157. [PubMed: 18587431] 
101. Diez-Campelo M, Perez-Simon JA, Perez J, et al. Minimal residual disease monitoring after allogeneic transplantation may help to individualize post-transplant therapeutic strategies in acute myeloid malignancies. Am.J.Hematol 2009;84:149-152. [PubMed: 19123459]

102. Warlick ED, O'Donnell PV, Borowitz M, et al. Myeloablative allogeneic bone marrow transplant using $\mathrm{T}$ cell depleted allografts followed by post-transplant GM-CSF in high-risk myelodysplastic syndromes. Leuk.Res 2008;32:1439-1447. [PubMed: 18261793]

103. Campregher PV, Gooley T, Scott BL, et al. Results of donor lymphocyte infusions for relapsed myelodysplastic syndrome after hematopoietic cell transplantation. Bone Marrow Transplant 2007;40:965-971. [PubMed: 17846603]

104. Rizzieri DA, Koh LP, Long GD, et al. Partially matched, nonmyeloablative allogeneic transplantation: clinical outcomes and immune reconstitution. J.Clin.Oncol 2007;25:690-697. [PubMed: 17228020]

105. Spitzer TR. Haploidentical stem cell transplantation: the always present but overlooked donor. Hematology 2005:390-395. [PubMed: 16304409]

106. Depil S, Deconinck E, Milpied N, et al. Donor lymphocyte infusion to treat relapse after allogeneic bone marrow transplantation for myelodysplastic syndrome. Bone Marrow Transplant 2004;33:531-534. [PubMed: 14716345]

107. Kang Y, Chao NJ, Aversa F. Unmanipulated or CD34 selected haplotype mismatched transplants (Review). Curr.Opin.Hematol 2008;15:561-567. [PubMed: 18832926]

108. Lim ZY, Pearce L, Ho AY, et al. Delayed attainment of full donor chimaerism following alemtuzumab-based reduced-intensity conditioning haematopoietic stem cell transplantation for acute myeloid leukaemia and myelodysplastic syndromes is associated with improved outcomes. Br.J.Haematol. prepublished online doi:10.1111/j.1365-2141.2007.06676.x.

109. Shaw BE, Mufti GJ, Mackinnon S, et al. Outcome of second allogeneic transplants using reducedintensity conditioning following relapse of haematological malignancy after an initial allogeneic transplant. Bone Marrow Transplant 2008;42:783-789. [PubMed: 18724393]

110. de Witte T, Oosterveld M, Muus P. Autologous and allogeneic stem cell transplantation for myelodysplastic syndrome (Review). Blood Rev 2007;21:49-59. [PubMed: 16822600]

111. Oosterveld M, Suciu S, Verhoef G, et al. The presence of an HLA-identical sibling donor has no impact on outcome of patients with high-risk MDS or secondary AML (sAML) treated with intensive chemotherapy followed by transplantation: results of a prospective study of the EORTC, EBMT, SAKK and GIMEMA Leukemia Groups (EORTC study 06921). Leukemia 2003;17:859_ 868. [PubMed: 12750698] 